Journal of Animal and Veterinary Advances 11 (18): 3289-3297, 2012

ISSN: $1680-5593$

(C) Medwell Journals, 2012

\title{
Antibacterial Activity and Mechanism of Pogostemon cablin Against Bacteria from Milk of Dairy Cows Suffering with Mastitis
}

\author{
${ }^{1,2}$ Min Dai, ${ }^{1}$ Cheng Peng, ${ }^{1}$ Feng Wan and ${ }^{3} \mathrm{Fu}$ Peng \\ ${ }^{1}$ State Key Laboratory of Systematic Research and \\ Exploitation of Traditional Chinese Medicine Resources, College of Pharmaceuticals, \\ Chengdu University of Traditional Chinese Medicine, Chengdu, 610075 Sichuan, P.R. China \\ ${ }^{2}$ School of Laboratory Medicine, Chengdu Medical College, Chengdu, 610083 Sichuan, P.R. China \\ ${ }^{3}$ School of Life Sciences, Sichuan University, Chengdu, 610064 Sichuan, P.R. China
}

\begin{abstract}
Minimum Inhibitory Concentrations (MICs) of 3 extracts and oil from Pogostemon cablin against isolates from milk produced by dairy cow with mastitis were determined by Agar Dilution Method. Water extract had low activity; ethanol extract and ethanol-water extract had moderate effects having MICs ranging from $25.0-100.0,12.5-100.0 \mathrm{mg} \mathrm{mL}{ }^{-1}$, respectively. Oil had strong activity against Gram-positive and Gram-negative isolates with MICs ranging from $0.2-8.2 \mathrm{mg} \mathrm{mL}^{-1}$. Oil also, showed strong efficacy in mouse peritonitis model infected with $S$. aureus or $E$. coli. Their actions were dose-dependent. Obvious morphological changes were observed by TEM in oil-treated $E$. coli or $S$. aureus such as a remarkable electron-light region small electron-dense granules disturbed cytoplasmic membrane and abnormal cell division. In conclusion, antibacterial substance of $P$. cablin was oil which had broad-spectrum antibacterial activities so to make it a potential candidate as antibacterial agent to treat bovine mastitis.
\end{abstract}

Key words: Pogostemon cablin, essential oil, bovine mastitis, in vitro and in vivo antibacterial activity, antibacterial mechanism, China

\section{INTRODUCTION}

Bovine mastitis is a major clinical problem because of the increasing presence of antibiotic-resistant bacteria and treatment failure (Kim et al., 2010) resulting in significant economic losses to the dairy industry (Chaneton et al., 2011). Owing to the deficiency of other effective antibacterial agents, intramammary infusion of antibiotics is the most common treatment method available for treating mastitis (Baskaran et al., 2009). Use of antibiotics against bacterial diseases may potentially lead to the emergence of antibiotic resistant strains of bacteria. Moreover, the use of antibiotics to treat bovine mastitis has been implicated as a common source of drug residues in milk. Approximately $90 \%$ of the residues detected in milk over a period of 5 years in Michigan, USA were originated from antibacterial therapy for mastitis (Erskine et al., 2003). To improve the safety of milk and dairy products there is a need for alternative approaches for controlling mastitis in dairy cows. Plant-based essential oils or organic extracts are well known to exhibit a wide range of biological activities but with low mammalian toxicity, less environmental effects and wide public acceptance (Paranagama et al., 2003).

Pogostemon cablin (P. cablin) originated in Malaysia and India was introduced into China for perfume and medicine and the Southern China's Guangdong province finally started culturing its own around the eleventh century. Up to date, $P$. cablin is widespread in Southern China including Guangdong (Guangzhou, Gaoyao, Zhanjiang) and Hainan provinces. The plant has been used as Chinese herbal medicine to remove dampness, relieve summer-heat, exterior syndrome, stop vomiting, stimulate appetite and treat common cold, nausea and diarrhea (Pharmacopeia Commission of PRC, 2004). And the oil is widely used in the cosmetic and oral hygiene industries to scent perfumes, flavor toothpaste, etc. (Zhao et al., 2005). Modern researches have repeatedly demonstrated various pharmacological activities of this oil including anti-emetic properties (Yang et al., 1999), trypanocidal activities (Kiuchi et al., 2004), anti-bacterial (Edwards-Jones et al., 2004; Liu et al., 2009), anti-fungal

Corresponding Author: Cheng Peng, College of Pharmaceuticals, Chengdu University of Traditional Chinese Medicine, Chengdu, 610075 Sichuan, P.R. China 
(Mo et al., 2004) and $\mathrm{Ca}^{2+}$ antagonist activities (Ichikawa et al., 1989). To search for natural antibacterial substances for treating mastitis, researchers investigated the in vitro antibacterial activity of extracts of $P$. cablin against isolates from milk produced by dairy cow with mastitis in vivo antibacterial activity and potential antibacterial mechanism of essential oil from $P$. cablin which had broad-spectrum activities so to make it a potential candidate as antibacterial agent.

\section{MATERIALS AND METHODS}

Antibiotics, media and reagents: Cefotaxime sodium was obtained from Sichuan Pharmaceutical, Inc. (China, Lot: 080301). Cefepime hydrochloride was obtained from Shandong Luoxin Pharmacy Stock Co. Ltd. (China, Lot: 0903238). Mueller-Hinton (MH) agar, yeast extract and tryptone were purchased from Oxoid Ltd. Mucin from porcine stomach (Type II) was obtained from Sigma. Polysorbate 80 were purchased from Chengdu Chang zheng Huabo., Ltd. (Chengdu, China).

Microorganisms: The bacteria were isolated from 80 milk samples produced by dairy cow with clinical or subclinical mastitis from Chengdu, Mianyang and Meishan, Sichuan province, China in 2008 . One hundred and twenty strains of isolates were identified by VITEK 32 Microbial Analytical System or Sequence Analysis of $16 \mathrm{~S}$ rRNA (Table 1). Reference strains of E. coli ATCC 25922 and $S$. aureus ATCC 25923 were provided by Sichuan

Table 1: In vitro antibacterial activity of 3 extracts and essential oil from $P$. calbin against bacteria from milk produced by dairy cow with mastitis

\begin{tabular}{|c|c|c|c|c|c|c|c|}
\hline \multirow[b]{2}{*}{ Species of bacteria } & \multirow[b]{2}{*}{$\mathrm{N}^{0}$} & \multicolumn{3}{|c|}{ Water extract ${ }^{a}$} & \multicolumn{3}{|c|}{ Ethanol extract ${ }^{a}$} \\
\hline & & MIC & $\mathrm{MIC}_{50}$ & $\mathrm{MIC}_{90}$ & MIC & $\mathrm{MIC}_{50}$ & $\mathrm{MIC}_{90}$ \\
\hline ATCC25923 & 1 & - & - & - & 100.0 & - & - \\
\hline S. aureus & 8 & $100.0 \sim *$ & - & $100.0 \sim *$ & $50.0 \sim 100.0$ & 100.0 & 100.00 \\
\hline Coagulase-negative Stophylococcus & 25 & $50.0 \sim *$ & - & $100.0 \sim *$ & $50.0 \sim 100.0$ & 100.0 & $50.0 \sim 100.0$ \\
\hline Kurthia gibsonii & 9 & - & - & - & $50.0 \sim 100.0$ & 100.0 & $50.0 \sim 100.0$ \\
\hline Bacillus & 9 & $25.0 \sim *$ & 100.0 & $100.0 \sim *$ & $50.0 \sim 100.0$ & 50.0 & $50.0 \sim 100.0$ \\
\hline Macrococcus caseolyticus & 6 & $25.0 \sim *$ & - & $25.0 \sim *$ & $50.0 \sim *$ & 50.0 & $50.0 \sim *$ \\
\hline Streptococcus ${ }^{\mathrm{d}}$ & 4 & $50.0 \sim "-"$ & - & $50.0 \sim *$ & $50.0 \sim 100.0$ & 100.0 & $50.0 \sim 100.0$ \\
\hline Corynebacterium & 3 & 12.5 & - & - & 25.0 & - & - \\
\hline Enterococcus faecalis & 2 & - & - & - & 100.0 & - & - \\
\hline ATCC 25922 & 1 & - & - & - & - & - & - \\
\hline E. coli & 17 & - & - & - & - & - & - \\
\hline Pseudomonad & 12 & $50.0 \sim *$ & - & $50.0 \sim *$ & $50.0 \sim *$ & 50.0 & $50.0 \sim *$ \\
\hline Presumptive Acinetobacter lwoffii & 11 & $100.0 \sim *$ & 100.0 & $100.0 \sim *$ & $25.0 \sim 100.0$ & 100.0 & $50.0 \sim 100.0$ \\
\hline Enterobacter cloacae & 6 & - & - & - & - & - & - \\
\hline Chrvseobacterium indologenes & 6 & 100.0 & 100.0 & 100.0 & 50.0 & 50.0 & 50.0 \\
\hline Shigella flexneri & 1 & 25.0 & - & - & 50.0 & - & - \\
\hline \multirow[t]{2}{*}{ Proteus vulgaris } & 1 & 100.0 & - & - & 100.0 & - & - \\
\hline & \multicolumn{4}{|c|}{ Ethanol-water extract ${ }^{\mathrm{a}}$} & \multicolumn{3}{|c|}{ Essential oil ${ }^{\mathrm{a}}$} \\
\hline Species of bacteria & \multicolumn{2}{|c|}{ MIC } & $\mathrm{MIC}_{50}$ & $\mathrm{MIC}_{90}$ & MIC & $\mathrm{MIC}_{50}$ & $\mathrm{MIC}_{90}$ \\
\hline ATCC25923 & \multicolumn{2}{|c|}{50.0} & - & - & 0.5 & - & - \\
\hline S. aureus & \multicolumn{2}{|c|}{$25.0 \sim 50.0$} & 50.0 & $25.0 \sim 50.0$ & $0.5 \sim 1.0$ & 0.5 & 0.5 \\
\hline Coagulase-negative Staphylococcus ${ }^{b}$ & \multicolumn{2}{|c|}{$12.5 \sim 100.0$} & $25.0 \sim 50.0$ & $12.5 \sim 50.0$ & $0.2 \sim 2.0$ & 0.5 & $0.3 \sim 0.5$ \\
\hline Kurthia gibsonii & \multicolumn{2}{|c|}{$25.0 \sim 50.0$} & 50.0 & $25.0 \sim 50.0$ & 0.5 & 0.5 & 0.5 \\
\hline Bacillus & \multicolumn{2}{|c|}{$25.0 \sim 50.0$} & 25.0 & $25.0 \sim 50.0$ & $0.3 \sim 0.5$ & 0.5 & 0.5 \\
\hline Macrococcus caseolyticus & \multicolumn{2}{|c|}{$25.0 \sim *$} & 25.0 & $25.0 \sim *$ & $0.3 \sim 0.5$ & $0.3 \sim 0.5$ & $0.3 \sim 0.5$ \\
\hline Streptococcus & \multicolumn{2}{|c|}{$25.0 \sim 50.0$} & 25.0 & $25.0 \sim 50.0$ & 0.5 & 0.5 & 0.5 \\
\hline Corynebacterium & \multicolumn{2}{|c|}{12.5} & - & - & 0.3 & - & - \\
\hline Enterococus faecalis & \multicolumn{2}{|c|}{100.0} & - & - & 1.0 & - & - \\
\hline ATCC 25922 & & & - & - & 2.0 & - & - \\
\hline E. coli & & & - & - & $0.3 \sim 8.2$ & 2.0 & $1.0 \sim 4.1$ \\
\hline Pseudomonad & & & $25.0 \sim 50.0$ & 25.0 "_"” & $0.3 \sim *$ & $0.3 \sim 2.0$ & $0.3 \sim *$ \\
\hline Presumptive Acinetobacter lwoffii & & & 25.0 & $25.0 \sim 50.0$ & $0.5 \sim 1.0$ & 0.5 & 0.5 \\
\hline Enterobacter cloacae & & & - & - & $4.1 \sim 8.2$ & 4.1 & 4.1 \\
\hline Chrvseobacterium indologenes & & & 25.0 & 25.0 & $0.3 \sim 1.0$ & 0.5 & $0.5 \sim 1.0$ \\
\hline Shigella flexneri & & & & & 0.3 & & \\
\hline Proteus vulgaris & & & & & 2.0 & & \\
\hline
\end{tabular}

"Minimum Inhibitory Concentration (MIC) ( $\mathrm{MIC}, \mathrm{MIC}_{50}, \mathrm{MIC}_{90}$ values in $\mathrm{mg} \mathrm{mL}^{-1}$ ). "." is no activity against corresponding isolates at maximum concentration and the maximum concentration of oil and other extracts were 32.7 and $100.0 \mathrm{mg} \mathrm{mL}^{-1}$, respectively. ${ }^{b} \mathrm{Twenty}$-five strains coagulase-negative Staphylococcus includes 5 strains Stophvlococcus auriculoris, 5 strains Stophylococcus Scqprophyticus, 4 strains Staephylococcus xylosus, 3 strains Staphylococcus sp., 2 strains Stophylococcus hominis, 1 strain Staphylococcus epidermidis, 1 strain Stophylococcus haemolyticus, 1 strain Staphylococcus warneri, 1 strain Stophylococcus cohnii, 1 strain Stophylococcus sciuri and 1 strain Staphylococcus nepalensis. ${ }^{c}$ Nine strains Bacillus includes 4 strains Bacillus cereus, 3 strains Bacillus pumilus and 2 strains Bacillus flexus. ${ }^{\mathrm{d}}$ Four strains Streptococcus includes 1 strain Streptococcus agalactice (Group B), 1

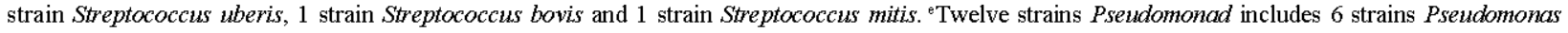
aeruginosa, 3 strains Sphingomonas paucimobilis, 2 strains Pseudomonas fluorescens and 1 strain Aeromonas hydrophila 
Industrial Institute of Antibiotics Co., Ltd. All Strains were stored until use in refrigerator at $-80^{\circ} \mathrm{C}$ in Luria-Bertani (LB) medium containing 10\% glycerol.

Laboratory animals: Specific Pathogen Free (SPF) Kun-ming mice (body weight, 18-22 g) were purchased from Chengdu Institute of Biological Products (Chengdu, China) and acclimatized for 1 day prior to use. All animals were housed in cages (five animals of the same sex per cage) under constant temperature $\left(25 \pm 2^{\circ} \mathrm{C}\right)$ and humidity $(50 \pm 10 \%)$ free to access food and water throughout the study. All studies with animals were approved by the Animal Research Committee of the Institute of Medicinal Biotechnology (Beijing, China).

\section{Preparation of essential oil and 3 extracts from $P$. cablin:}

$P$. cablin from Guangdong province, China was purchased from Beijing Tongren Drug Store and identified by Prof. Min Li at Chengdu University of Traditional Chinese Medicine. The essential oil was obtained by steam distillation and the density of oil was $0.98 \mathrm{mg} \mathrm{mL}^{-1}$ (Pharmacopeia Commission of PRC, 2004). Water extract (or ethanol extract) was extracted as follows: $P$. cablin ( $150 \mathrm{~g}$ ) was extracted with $1,200 \mathrm{~mL}$ of distilled water [or $75 \%(\mathrm{v} / \mathrm{v}) \mathrm{EtOH}$ ] for $2 \mathrm{~h}$ with the method of thermal circumfluence extraction. The heated decoction was filtered and the first filtrate was collected in a separate flask. The remnant was extracted repeatedly one more time. The first and second filtrates were combined and concentrated. While ethanol-water extract was extracted as follows: P. cablin (150 g) was first extracted with $1,200 \mathrm{~mL} 75 \%(\mathrm{v} / \mathrm{v})$ ethanol for $2 \mathrm{~h}$ with the method of thermal circumfluence extraction then the remnant was extracted with $1,200 \mathrm{~mL}$ of distilled water for $2 \mathrm{~h}$ as the same method described above. The ethanol-water extract was obtained from the mixture of filtrates of ethanol extract and water extract followed by concentration. The concentration of three extracts was adjusted to $1.5 \mathrm{~g} \mathrm{~mL}^{-1}$ with distilled water. The oil and 3 extracts were stored at $-20^{\circ} \mathrm{C}$ until use. The concentrations of 3 extracts were calculated as follows:

$$
\text { The concentration of extract }=\frac{\text { Weight of } P . \operatorname{cablin}(\mathrm{g})}{\text { Volume of extract }(\mathrm{mL})}
$$

In vitro antibacterial activities of extracts and oil from $P$. cablin: Minimum Inhibitory Concentrations (MICs) of 3 kinds of extracts and essential oil from $P$. cablin against the tested microorganisms were determined by the agar dilution method as described by the Clinical and Laboratory Standards Institute
(CLSI, 2008; Hayouni et al., 2008; Mimee et al., 2009; Yayli et al., 2010) with modification. The assay was carried out as follows. Water extract, ethanol extract and ethanol-water extract were diluted in distilled water and oil was dissolved with polysorbate 80 (final concentration $1 \%$ ). Microbial strains were cultured overnight at $35^{\circ} \mathrm{C}$. Test strains were suspended in physiological saline to give a final density of $1.5 \times 10^{6} \mathrm{CFU} \mathrm{mL}^{-1}$ by VITEK DENSICHEK (BioMerieux, Inc.).

All tests were performed in $\mathrm{MH}$ agar. Geometric dilutions ranging from $1.6-100.0 \mathrm{mg} \mathrm{mL}^{-1}$ of water extract, ethanol extract and ethanol-water extract and from $0.1-32.7 \mathrm{mg} \mathrm{mL}^{-1}$ of essential oil were prepared in $90 \mathrm{~mm}$ plate (Kangjian Medical Apparatus Co., Ltd.) including one growth control $(\mathrm{MH}$ agar + distilled water or $1 \%$ polysorbate 80$)$ and one sterility control $(\mathrm{MH}$ agar + distilled water + extract or $\mathrm{MH}$ agar $+\%$ polysorbate $80+$ oil). Each bacterial suspension was inoculated on the plates by SAKUMA Anti-bacterial Determiner (Japan). The plates were incubated at $35^{\circ} \mathrm{C}$ for $24 \mathrm{~h}$ and $\mathrm{M} C$ s were then determined as the lowest concentration at which no bacteria growth was apparent in a given plate. The test was repeated three times. The data were expressed as the mean \pm SD. Statistical evaluation for differences among multiple extracts or bacterial species was carried out using one way Analysis of Variance (ANOVA) by SPSS for windows (SPSS 13.0; SPSS Inc., Chicago, IL, USA). The $\mathrm{p}<0.05$ was considered significant statistically and $\mathrm{p}<0.01$ was considered very significant statistically.

\section{In vivo antibacterial activities of patchouli oil against} isolates of $E$. coli and $S$. aureus: In vivo efficacy of patchouli oil against mouse systemic infections was evaluated with one isolate of $S$. aureus or $E$. coli, respectively. Effective concentration levels of patchouli oil, Minimal Lethal Doses (MLDs) of tested S. aureus and $E$. coli were determined by using a preliminary test. The in vivo antibacterial activity experiment was carried out according to a described method with modification (Li et al., 2010). Mice were randomly divided into 6 parallel groups for each isolate and each group had 10 mice including 5 males and 5 females. There were one model group (drug negative to show the success of modeling), one control group (growth control), three experimental drug groups including high dose group $(0.49 \mathrm{~g} / \mathrm{kg} /$ day $)$ mid dose group $(0.25 \mathrm{~g} / \mathrm{kg} /$ day $)$ and low dose group $(0.13 \mathrm{~g} / \mathrm{kg} /$ day) and one antibiotic group (positive) in which cefepime was used in model infected with $S$. aureus and cefotaxime was in that infected with E. coli. Patchouli oil, antibiotic and physiological saline were administered intramuscularly for experimental drug groups, positive dug group model group and control 
group once daily for 6 days, respectively. Except for the mice of control group other mice were infected intraperitoneally with Minimal Lethal Dose (MLD) of bacterial suspension in 5\% mucin (Sigma) after the sixth administration of drugs or physiological saline. The MLDs of $S$. aureus and E. coli were $1.3 \times 10^{8}, 1.5 \times 10^{4}$ CFU $\mathrm{g}^{-1}$, respectively. Survivals in each group were recorded daily for 14 days. The test was repeated three times.

Growth curves of oil-treated $E$. coli and $S$. aureus: Inhibitory of the growth of E. coli ATCC25922 or S. aureus ATCC25923 after oil treatment was investigated. Patchouli oil was first emulsified with polysorbate 80 then diluted with Luria-Bertani broth to reach the final concentration of $1 / 2 \mathrm{MIC}\left(1.02 \mathrm{mg} \mathrm{mL}^{-1}\right.$ for E. coli, $0.26 \mathrm{mg} \mathrm{mL}^{-1}$ for $S$. aureus $), 1 / 4 \mathrm{IC}\left(0.51 \mathrm{mg} \mathrm{mL}^{-1}\right.$ for $E$. coli, $0.13 \mathrm{mg} \mathrm{mL}^{-1}$ for $S$. aureus) and $1 / 8 \mathrm{MIC}$ (0.26 mg mL $\mathrm{mg}^{-1}$ for $E$. coli, $0.07 \mathrm{mg} \mathrm{mL}^{-1}$ for $S$. aureus), respectively. The oil control group had the same concentration of oil but without corresponding bacterial suspension and the control group had bacterial suspension in LB broth containing $1 \%$ polysorbate 80 but without oil. All preparations were incubated with $1.5 \times 10^{6}$ $\mathrm{CFU} \mathrm{mL}{ }^{-1}$ at $37^{\circ} \mathrm{C}$ with shaking at $150 \mathrm{rpm}$ and $100 \mu \mathrm{L}$ aliquots were then transferred to a 96 well microtitre plate at $2 \mathrm{~h}$ intervals. $O D_{600}$ values were monitored by using VARIOSKAN Flash (Thermo Scientific) until $O_{600}$ value of each group reached stationary phase. The final $\mathrm{OD}_{600}$ value at each time of each experimental group equaled to the mean of $\mathrm{OD}_{600}$ value of experimental group minus that of oil control under the same condition. The growth curve of oil-treated $E$. coli or $S$. aureus was made using Microsoft Excel in which the growth time was defined as horizontal ordinate and the $\mathrm{OD}_{600}$ value was defined as vertical coordinate. All analyses were carried out in triplicate.

Ultrastructural changes of oil-treated $E$. coli and S. aureus: After oil treatment, the ultrastructural changes of E. coli ATCC25922 or S. aureus ATCC25923 were observed by transmission electron microscopy. Tested bacterial inocula were prepared by inoculating followed by culturing overnight at $35^{\circ} \mathrm{C}$, the logarithmic phase bacteria containing $1.5 \times 10^{6} \mathrm{CFU} \mathrm{mL}^{-1}$ were inoculated in LB broth containing $1 / 2 \mathrm{MLC}$ patchouli oil and cultured at $35^{\circ} \mathrm{C}, 150 \mathrm{rpm}$ for $18 \mathrm{~h}$. And logarithmic phase bacteria of control group were inoculated in LB broth. Cells were centrifuged at $1,000 \mathrm{~g}$ at $4^{\circ} \mathrm{C}$ for $10 \mathrm{~min}$. The samples were fixed with $\mathrm{PBS}(\mathrm{pH} 7.4)$ containing $0.5 \%$ glutaraldehyde for $30 \mathrm{~min}$ at $4^{\circ} \mathrm{C}$. Subsequently, the cells were centrifuged at $15,000 \mathrm{~g}$ at $4^{\circ} \mathrm{C}$ for $10 \mathrm{~min}$ and the bacterial pellets were added to PBS ( $\mathrm{pH} 7.4$ ) containing $3 \%$ glutaraldehyde at $4^{\circ} \mathrm{C}$ for $1 \mathrm{~h}$. The cells were then postfixed in $1 \%$ buffered osmium tetroxide for $1 \mathrm{~h}$, stained with $1 \%$ uranyl acetate and dehydrated in a graded series of ethanol. The samples were cryofixed with a pressure of about 2100 bars and a reduction in temperature of $8^{\circ} \mathrm{C} \mathrm{sec}^{-1}$. The cryofixed cells were kept in liquid nitrogen and cryosubstituted in pure acetone containing $2 \%$ of osmium tetroxide and $0.1 \%$ of uranyl acetate for $72 \mathrm{~h}$ at $-90^{\circ} \mathrm{C}$. The temperature was gradually increased to $4^{\circ} \mathrm{C}\left(5^{\circ} \mathrm{C} \mathrm{h}^{-1}\right)$. Samples were kept at this temperature for $2 \mathrm{~h}$ followed by $2 \mathrm{~h}$ at room temperature and were then washed twice with acetone. The fixed cells of the two microorganisms were then embedded in L R (London Resin Co., Ltd.) white resin. Ultra-thin sections were prepared and stained with $1 \%$ uranyl acetate and sodium citrate. Microscopy was performed with Tecnai G2 F20 at the Analytical and Testing Center, Sichuan University (Sichuan, China).

\section{RESULTS AND DISCUSSION}

\section{In vitro antibacterial activities of 3 extracts and essential} oil from $P$. cablin: Pogostemon cablin (Blanco) Benth. known as Guang-Huo-Xiang is a Chinese medical material traditionally used for the treatment of common cold, nausea and diarrhea (Wei and Shibamoto, 2007). It is a potentially useful source of antimicrobial compounds. Earlier reports showed that patchouli oil inhibited the growth of some bacterial strains in the genera S. aureus, Pseudomonas aeruginosa, dysentery bacterium (Liu et al., 2009) and plant pathogenic fungi (Mo et al., 2004). Water extract of $P$. cablin inhibited the growth of some bacterial strains in the genera $S$. aureus, Enterobacteriaceae (Liu et al., 1999) but no effect on E. coli (Luo, 2005). The results reported from different studies are difficult to compare, presumably because of different test methods, bacterial strains and sources of samples used. And there were not reports on antibacterial activity of $P$. cablin against isolates stains from milk cows with mastitis.

To assess the antibacterial substance of traditional Chinese medicine $P$. cablin, the MICs of 3 extracts and oil of $P$. cablin cultivated in Guangdong province, China against 120 strains isolates were tested. The results showed that essential oil had the highest activity against 117 strains of clinical Gram-positive and gram-negative bacteria except for 3 strains of Pseudomonad with the MICs ranging from $0.2-8.2 \mathrm{mg} \mathrm{mL}^{-1}$ (Table 1). Ethanol extract and ethanol-water extract had comparatively moderate antibacterial activities against a majority of Gram positive and negative bacteria with $\mathrm{MIC}_{90}$ values of $50.0-100.0$ and $12.5-50.0 \mathrm{mg} \mathrm{mL}^{-1}$, respectively but no 
J. Anim. Vet. Adv., 11 (18): 3289-3297, 2012

Table 2: Comparative analysis on MICs of 2 extracts and essential oil from P. cablin (mean $\pm \mathrm{SD}$ )

\begin{tabular}{|c|c|c|c|c|}
\hline Species of bacteria & $\mathrm{N}^{0}$ & $\begin{array}{l}\text { Ethanol } \\
\text { extract }^{\mathrm{a}}\end{array}$ & $\begin{array}{c}\text { Ethanol-water } \\
\text { extract }^{\mathrm{a}}\end{array}$ & $\begin{array}{c}\text { r Essential } \\
\text { oil }\end{array}$ \\
\hline $\begin{array}{l}\text { Staphylococcus cureus } \\
\text { Coagulase-negative }\end{array}$ & 8 & $92.9 \pm 18.9$ & $42.9 \pm 12.2^{\mathrm{B}}$ & $0.6 \pm 0.2^{\mathrm{BC}}$ \\
\hline Staphylococcus & 25 & $84.6 \pm 23.5$ & $39.9 \pm 22.6^{\mathrm{B}}$ & $0.6 \pm 0.3^{\mathrm{BC}}$ \\
\hline Kurthia gibsonii & 9 & $87.5 \pm 23.1$ & $40.6 \pm 12.9^{\mathrm{B}}$ & $0.5 \pm 0.0^{\mathrm{BC}}$ \\
\hline Macrocaccus caseolyticus & 6 & $60.0 \pm 22.4$ & $25.0 \pm 0.00$ & $0.3 \pm 0.1^{\mathrm{bC}}$ \\
\hline Streptococcus & 4 & $87.5 \pm 25.0$ & $31.3 \pm 12.5^{b}$ & $0.5 \pm 0.0^{\mathrm{bc}}$ \\
\hline Bacillus & 9 & $61.1 \pm 22.1$ & $33.3 \pm 12.5^{b}$ & $0.5 \pm 0.1^{\mathrm{BC}}$ \\
\hline Escherichia coli & 17 & - & - & $3.1 \pm 2.2$ \\
\hline $\begin{array}{l}\text { Pseudomonad } \\
\text { Presumptive }\end{array}$ & 12 & $62.5 \pm 23.1$ & $37.5 \pm 13.4$ & $1.7 \pm 2.5^{\mathrm{BC}}$ \\
\hline Acinetobacter lwoffii & 11 & $77.5 \pm 29.9$ & $37.5 \pm 13.2^{b}$ & $0.6 \pm 0.2^{\mathrm{BC}}$ \\
\hline Enterobacter cloacae & 6 & - & - & $4.8 \pm 1.7$ \\
\hline Chrvseobacterium indologenes & 6 & $50.0 \pm 0.00$ & $25.0 \pm 0.00^{\mathrm{B}}$ & $0.6 \pm 0.3^{\mathrm{BC}}$ \\
\hline
\end{tabular}

effect on E. coli and Enterobacter cloacae (Table 1). The antibacterial activity of ethanol-water extract against Staphylococcus, Kurthia gibsonii, Streptococcus and Presumptive Acinetobacter lw offii was stronger than that of ethanol extract $(\mathrm{p}<0.05, \mathrm{p}<0.01)$ (Table 2$)$. Water extract obtained by traditional decoction showed the lowest antibacterial activity having no activity on the majority of tested bacteria without activity against $E$. coli as earlier study (Luo, 2005). Therefore, in vitro antibacterial substance of Pogostemon cablin cultivated in Guangdong, China was mainly its oil obtained by steam distillation which showed potent and broad-spectrum in vitro antibacterial activity against both gram-positive isolates (Staphylococcus, Streptococcus, Kurthia gibsonii, Macrococcus caseolyticus, bacillus, etc.) and Gram-negative isolates (E. coli, Enterobacter cloacae, Presumptive Acinetobacter lwoffii, Pseudomonad, Chrvseobacterium indologenes, Proteus vulgaris and Shigella flexneri). But the effect of the oil on grampositive isolates was higher than that on gram-negative isolates. Furthermore, in the earlier study, resistance analyses of 120 isolates on penicillin, tetracycline, erythromycin, streptomycin, gentamicin, cephalothin, cefotaxime, ciprofloxacin were analyzed. The results showed that 91 strains of bacteria had resistance to 8 experimental antibiotics in which $64.8 \%$ (59/91) isolates showed multi-drug resistance. While patchouli oil had the same activity against resistant isolates compared to sensitive isolates. Therefore, patchouli oil may be a significant antibacterial agent in controlling resistant pathogenic infections, especially multi-drug resistant pathogenic infections.

In vivo antibacterial activities of patchouli oil against E. coli and S. aureus: Based on the strong activity in vitro of patchouli oil in vivo efficacy of patchouli oil
Table 3: In vivo efficacy of patchouli oil against $E$. coli

\begin{tabular}{lccccc}
\hline Groups & No. of mice & Drug $^{\mathrm{a}}$ & $\begin{array}{c}\text { Dose } \\
(\mathrm{g} / \mathrm{kg} / \text { day })^{\mathrm{a}}\end{array}$ & $\begin{array}{c}\text { No. of } \\
\text { survival }\end{array}$ & $\begin{array}{r}\text { Survive } \\
\text { rate }(\%)\end{array}$ \\
\hline Control & 10 & - & - & 10 & 100.00 \\
Model & 10 & - & - & 0 & 0.00 \\
Antibiotic & 10 & Cefotaxime & 2.00 & 10 & 100.00 \\
High dose & 10 & Patchouli oil & 0.49 & 10 & 100.00 \\
Mid dose & 10 & Patchouli oil & 0.25 & 6 & 60.00 \\
Low dose & 10 & Patchouli oil & 0.13 & 4 & 40.00 \\
\hline
\end{tabular}

Table 4: In vivo efficacy of patchouli oil against $S$ caureus

\begin{tabular}{lccccc}
\hline Groups & No. of mice & Drug $^{\mathrm{a}}$ & $\begin{array}{c}\text { Dose } \\
(\mathrm{g} / \mathrm{kg} / \text { day })^{\mathrm{a}}\end{array}$ & $\begin{array}{c}\text { No. of } \\
\text { survival }\end{array}$ & $\begin{array}{r}\text { Survive } \\
\text { rate }(\%)\end{array}$ \\
\hline Control & 10 & - & - & 10 & 100.0 \\
Model & 10 & - & - & 0 & 0.0 \\
Antibiotic & 10 & Cefepime & 2.00 & 10 & 100.0 \\
High dose & 10 & Patchouli oil & 0.49 & 10 & 100.0 \\
Mid dose & 10 & Patchouli oil & 0.25 & 10 & 100.0 \\
Low dose & 10 & Patchouli oil & 0.13 & 10 & 100.0
\end{tabular}

a-: Indicates that the mice in the group had been given to saline

from P. cablin cultivated in Guangdong, China against $S$. aureus or $E$. coli was firstly investigated with mouse systemic infection model in this study. Patchouli oil showed potent and broad-spectrum in vivo activity against both E. coli (Table 3) and S. aureus (Table 4). All mice infected with $S$. aureus or $E$. coli could survive if patchouli oil $(0.49 \mathrm{~g} / \mathrm{kg} /$ day $)$ was administered intramuscularly for 6 days. The activity of patchouli oil against infection with $S$. aureus was stronger than that against $E$. coli. At different doses of high $(0.49 \mathrm{~g} / \mathrm{kg} /$ day $)$, mid $(0.26 \mathrm{~g} / \mathrm{kg} /$ day $)$ low $(0.13$ $\mathrm{g} / \mathrm{kg} /$ day), the survival rates of mice infected with $S$. aureus or the survival rates of mice infected with $S$. aureus or E. coli were 100.0, 100.0, 60.0 and $40.0 \%$, respectively. On the other hand, the survival rates of mice infected with S. aureus were all $100.0 \%$. Its action against E. coli was dose-dependent. However, patchouli oil had higher in vivo anti $S$. aureus activity than that of anti $E$. coli. Furthermore, the tested $S$. aureus and E. coli were isolated from milk produced by dairy cow with clinical mastitis and resistant to antibiotics and it showed that patchouli oil had in vivo antibacterial actions against resistant bacteria. The in vivo effects of patchouli oil against bacteria were in accordance with its in vitro activities.

The result of preliminary test observed patchouli oil had weak therapeutical effect on mouse systemic infection model. But it had very good preventive effects on mouse systemic infection model. The reason of results may be slowly absorbed of patchouli oil. Patchouli oil showed the muscle stimulation and mucous membrane irritation on the animals at high concentration in the study. The use of patchouli oil at low concentration $(1.5 \%)$ was free from side effects. However, owing to the methods of intramammary infusion and intramuscular injection used 


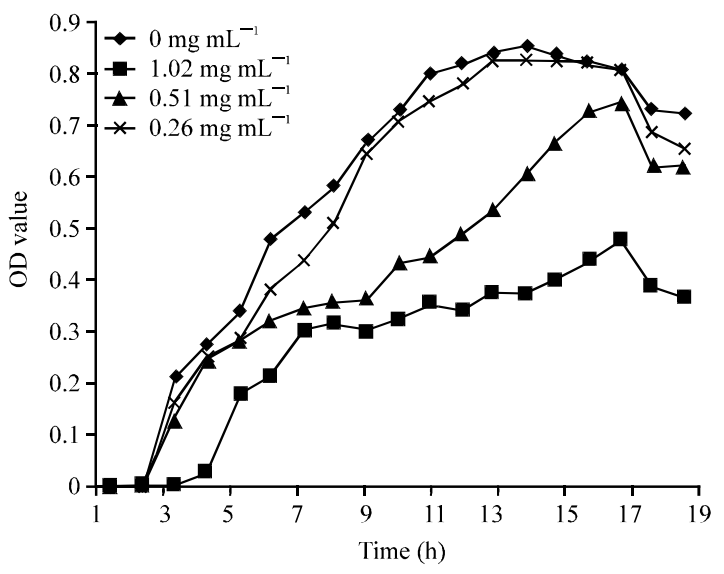

Fig. 1: Effect of different concentrations of patchouli oil on the growth of $E$. coli ATCC25922

in treat mastitis of drugs, patchouli oil was administered intramuscularly. In fact, the subsequent researches showed that $1.5 \%$ patchouli oil was used in intramammary infusion and intramuscular injection, showed good therapeutical effect on the dairy cow clinical mastitis and low side effects at New Hope Demonstration Dairy Cow Farm (Hongya county, Sichuan province, China).

Effect of patchouli oil on the growth of $E$. coli and S. aureus: At different concentrations (1/2 MIC, $1 / 4 \mathrm{MIC}$, $1 / 8 \mathrm{MIC}$ ) of patchouli oil, the growth of $E$. coli and $S$. aureus could be inhibited. Their lag phase times of $E$. coli and $S$. aureus were distinctively prolonged at sub-MIC value of oil, the inhibitory actions were of concentration-dependent. The result was in accordance with its in vivo properties. Therefore, the essential oil from $P$. cablin may be a potential candidate as a therapeutic agent and can be further developed as a constituent for treating bovine mastitis.

The effect of patchouli oil on the growth of $E$. coli ATCC25922 was shown in Fig. 1 which showed an obvious concentration-dependent effect of patchouli oil on $E$. coli. At the $1 / 2 \mathrm{MIC}\left(1.02 \mathrm{mg} \mathrm{mL}^{-1}\right)$ value for the condition, patchouli oil could obviously reduce the $E$. coli cell population compared with control sample. At the peak of log-phase bacteria, the OD value of untreated sample was about two times that of the oil-treated $E$. coli at the concentration of $1.02 \mathrm{mg} \mathrm{mL}^{-1}$. The growth curve of E. coli at the concentration of $0.26 \mathrm{mg} \mathrm{mL}^{-1}$ was almost in accordance with that of untreated group. Besides, patchouli oil could prolong the lag phase time of $E$. coli to $7 \mathrm{~h}$ at high concentration $\left(1.02 \mathrm{mg} \mathrm{mL}{ }^{-1}\right)$. However, the lag phase time of $E$. coli at lower concentration ( 0.51 or $0.26 \mathrm{mg} \mathrm{mL}^{-1}$ ) was almost consistent with that of

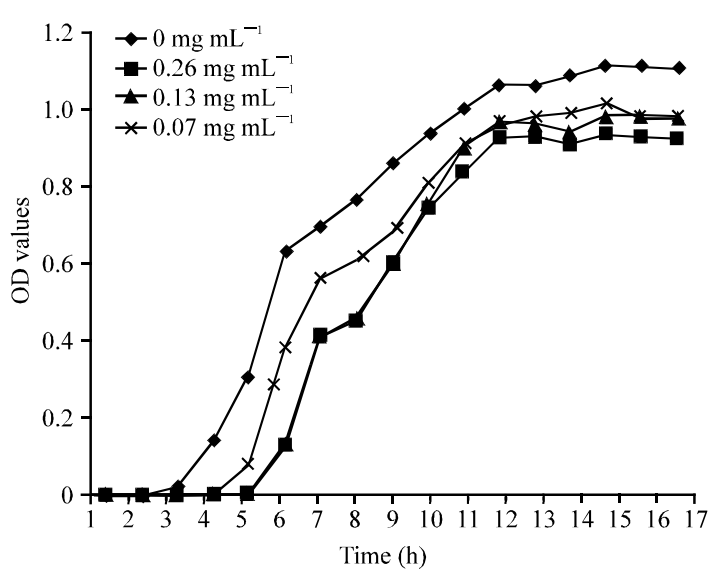

Fig. 2: Effect of different concentrations of patchouli oil on the growth of S. aureus ATCC25923

untreated E. coli. Effect of patchouli oil on the growth of S. aureus ATCC25923 was shown in Fig. 2. Besides the similar concentration-dependent effect on $S$. aureus to that found on $E$. coli, obvious differences were also observed in $S$. aureus after identical treatment. Compared with untreated group, $S$. aureus cell population only showed light decrease at different concentrations of patchouli oil. But patchouli oil could distinctly prolong all the lag phase time of S. aureus at high $\left(0.26 \mathrm{mg} \mathrm{mL}^{-1}\right)$, mid $\left(0.13 \mathrm{mg} \mathrm{mL}^{-1}\right)$, low $\left(0.07 \mathrm{mg} \mathrm{mL}^{-1}\right)$ concentration to $11 \mathrm{~h}$ while the lag phase time of $S$. aureus oil-untreated was $6 \mathrm{~h}$ in control group.

Morphological changes of $E$. coli and $S$. aureus after patchouli oil treatment: TEM observations revealed some important ultrastructural changes in patchouli oil-treated cells of E. coli (Fig. 3) and S. aureus (Fig. 4) compared with untreated control. Figure 3 a showed the internal structure of untreated $E$. coli cell. It was clear that the cells showed unanimous electron density suggesting that the cells were in normal condition without environment disturbance. Significant morphological changes occurred in E. coli cells after the addition of patchouli oil. Figure 3a-c gave an overview of oil-treated cells while Fig. 3d-p shown separate single damaged cells of them. The cytoplasmic membrane showed several sites of disruption and appeared notably disturbed. A big gap existed between the cytoplasmic membrane and the cell wall of the oil-treated E. coli cells. Patchouli oil entered into the center of $E$. coli cell through damaged cytoplasmic membrane and the big gap. Further, patchouli oil could possibly destroy the cytoplasmic inclusion and DNA molecules of the cell. A remarkable electron-light region often appeared in the center of the $E$. coli cells treated with patchouli oil. 


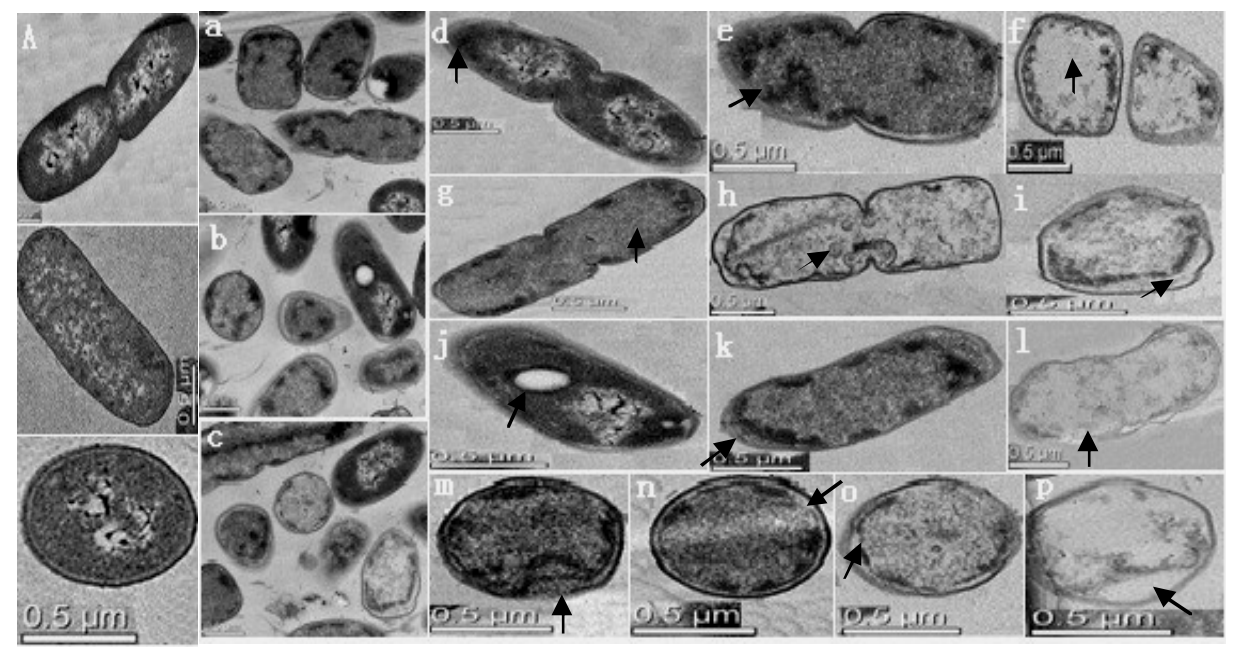

Fig. 3: Transmission electron micrographs of $E$. coli ATCC25922 treated with sub-MIC patchouli oil $\left(1.02 \mathrm{mg} \mathrm{mL}^{-1}\right)$; a) Ultra-structure of the untreated $E$. coli cell; a-p) Ultrastructure changes of $E$. coli cell oil-treated; a-c) Overview of $E$. coli cell oil-treated; d, e, $\mathrm{n}$ and o) Damaged cytoplasm membrane (arrow); $\mathrm{f}$ and $\mathrm{g}$ ) A remarkable electron-light region (arrow) in the center of the cell; $h$ and j) Patchouli oil entered into the center of the cell through damaged membrane; i, n, o and p) A big gap between the cytoplasm membrane and the cell wall was formed (arrow). $\mathrm{k}-\mathrm{m}$ ) The cell wall was seriously damaged (arrow)

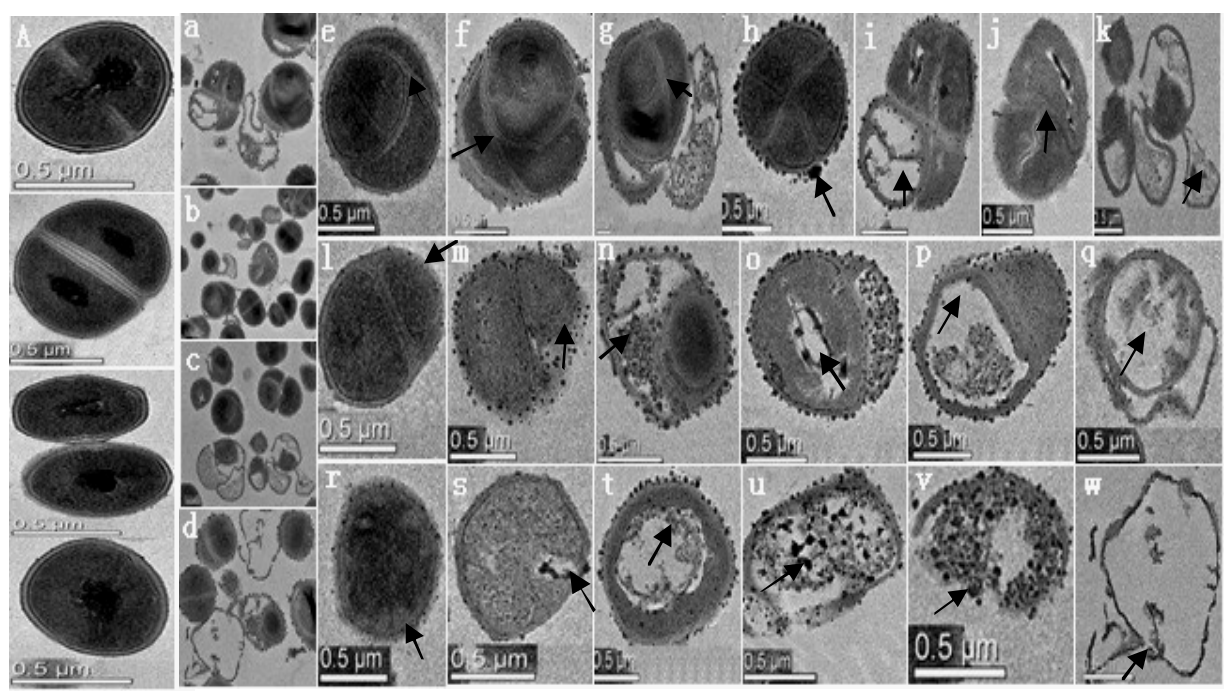

Fig. 4: Transmission electron micrographs of S. aureus ATCC25923 treated with sub-MIC patchouli oil $\left(0.26 \mathrm{mg} \mathrm{mL}^{-1}\right)$; a) Internal structure of the untreated $S$. aureus cell; a-w) Ultrastructure changes of $S$. aureus cell oil-treated; a-d) Overview of $S$. aureus oil-treated cell; e-j) Abnormal division of $S$. aureus, m) Damaged cytoplasm membrane (arrow); u-w) Damaged cell wall (arrow); i, p, q, t and s) A remarkable electron-light region in the center of the cell; $\mathrm{h}, \mathrm{m}, \mathrm{n}, \mathrm{o}, \mathrm{p}$ and t) Electron-dense granule around the cell wall; $\mathrm{u}$ and v) A cell composed of a great amount of large electron-dense granule; k) Cell debris by abnormal division of the cell (arrow)

S. aureus is a typical gram-positive bacterium which has a thicker cell wall compared with $E$. coli, a typical Gram-negative bacterium. Besides the similar morphological changes between these two typical types of bacteria, For instance there was an electron-light region in the center of the treated cell and the cell 
wall (Fig. $4 \mathrm{u}$ and $\mathrm{v}$ ) and the cytoplasmic membrane (Fig. $4 \mathrm{~m}$ ) of the treated cell had been damaged to some degrees. Obvious differences were observed between $S$. aureus and $E$. coli after identical treatment. First, there were various cell division in $S$. aureus including quaternary fission, tertiary fission, binary fission and so on (Fig. 4e-j).

At the same time, an electron-light region occurred in the nuclear region of the S. aureus cell. From that researchers propose that patchouli oil may act on the DNA of the $S$. aureus cell and give rise to cell division abnormalities of $S$. aureus. Second, there were many electron-dense granules around the cell wall of $S$. aureus seen clearly in Fig. 4 h, m, n, o, p and t, the granules also, existed in the cytoplasm (Fig. $4 \mathrm{u}, \mathrm{v}$ ). But there were no electron-dense granules in the electron-light region. It was very interesting to observe that a large amount of electron-dense granules appeared to surround the electron-light region but not within the region. In contrast, no electron-dense granules were found in the control samples or in oil-treated $E$. coli cells.

It is suggested that the discrepancy in action between $S$. aureus and $E$. coli may result from different structure of the two typical bacteria. The structural diversity may contribute to dissimilar efficacy in vivo and in vitro of patchouli oil against both Gram-positive $S$. aureus and Gram-negative E. coli. It was reported that Gram-negative bacteria were more resistant to plant-based essential oils than Gram-negative bacteria (Smith-Palmer et al., 1998). According to the earlier antibacterial activity studies on the extracts of Traditional Chinese Medicines (TCM) (Dai et al., 2011), researchers found that Gram-positive isolates were more sensitive than Gram-negative isolates to extracts from TCM.

This study indicated that ethanol extract, ethanolwater extract and oil from $P$. cablin had higher antibacterial activities against Gram-positive isolates than those against Gram-negative isolates. It is also indicated that antibacterial substance of $P$. cablin may be liposoluble constituents. The hydrophilic cell wall structure of gram-negative bacteria is constituted of essentially a Lipopolysaccharide (LPS) that screens out the hydrophobic oil and avoids the accumulation of liposoluble constituents in the target cell membrane. This may be the reason that Gram-positive isolates were found to be more sensitive than Gram-negative bacteria. The presumption is in agreement with antibacterial properties of patchouli oil which had higher in vitro and in vivo antibacterial activity against Gram-positive $S$. aureus than against gram-negative $E$. coli.

\section{CONCLUSION}

This study provides the adequate evidence indicating in vitro and in vivo antibacterial activities of patchouli oil from $P$. cablin against isolates from milk produced by dairy cow with mastitis. We suggest that essential oil from $P$. cablin was the antibacterial substance of $P$. cablin may be a potential candidate as a therapeutic agent and can be further developed as a constituent for antibacterial products, especially in treating bovine mastitis. Besides, the oil may be an antiseptic agent for preserving food.

\section{ACKNOWLEDGEMENTS}

Researchers thank Dr. Gui-Ping Yuan for her support and technical assistance of TEM at Analytical and Testing Center, Sichuan University. The study was funded by the National Key Technology and Program in the 11th Five Year Plan of China (2009BAI84B04).

\section{REFERENCES}

Baskaran, S.A., G.W. Kazmer, L. Hinckley, S.M. Andrew and K. Venkitanarayanan, 2009. Antibacterial effect of plant-derived antimicrobials on major bacterial mastitis pathogens in vitro. J. Dairy Sci., 92: 1423-1429.

CLSI, 2008. Performance standards for antimicrobial susceptibility testing. 18th Informational Supplement 2008CLSI Document No. M100-S18.

Chaneton, L., J.M. Perez Saez and L.E. Bussmann, 2011. Antimicrobial activity of bovine $\beta$-lactoglobulin against mastitis-causing bacteria. J. Dairy Sci., 94: 138-145.

Dai, M., C. Peng, F. Wan and D.D. Chen, 2011. Comparative study on antibacterial activity in vitro of 5 kinds of astringent therapy herbs against pathogenic bacteria from dairy cow with mastitis. China Dairy Ind., 39: 41-44.

Edwards-Jones, V., R. Buck, S.G. Shawcross, M.M. Dawson and K. Dunn, 2004. The effect of essential oils on methicillin-resistant Staphylococcus aureus using a dressing model. Burns, 30: 772-777.

Erskine, R.J., S. Wagner and F.J. DeGraves, 2003. Mastitis therapy and pharmacology. Vet. Clin. North Am. Food Anim. Pract., 19: 109-138.

Hayouni, E. A., I. Chraief, M. Abedrabba, M. Bouix, J.Y. Leveau, H. Mohammed and M. Hamdi, 2008. Tunisian Salvia officinalis L. and Schinus molle L. essential oils: Their chemical compositions and their preservative effects against Salmonella inoculated in minced beef meat. Int. J. Food Microbiol., 125: 242-251. 
Ichikawa, K., T. Kinoshita and U. Sankawa, 1989. The screening of Chinese crude drugs for $\mathrm{Ca} 2+$ antagonist activity: Identification of active principles from the aerial part of Pogostemon cablin and the fruits of Prunus mume. Chem. Pharm. Bull., 37: 345-348.

Kim, S. Y., S. Shin, H. C. Koo, J. H. Youn, H. D. Paik and Y.H. Park, 2010. In vitro antimicrobial effect and In vivo preventive and therapeutic effects of partially purified lantibiotic lacticin NK34 against infection by Staphylococcus species isolated from bovine mastitis. J. Dairy Sci., 93: 3610-3615.

Kiuchi, F., K. Matsuo, M. Ito, T.K. Qui and G. Honda, 2004. New sesquiterpene hydroperoxides with trypanocidal activity from Pogostemon cablin. Chem. Pharm. Bull., 52: 1495-1496.

Li, C.R., Y. Li, G.Q. Li, X.Y. Yang and W.X. Zhang et al., 2010. In vivo antibacterial activity of nemonoxacin, a novel non-fluorinated quinolone. J. Antimicrob. Chemother., 65: 2411-2415.

Liu, H.H., J.P. Luo and P.L. Lai, 1999. Studies on the anti-enteropathogenic bacteria action of herba Pogostemonis extracts. Zhong Yao Cai, 22: 408-411.

Liu, X.R., M.C. Deng and Y.Y. Zhang, 2009. Extraction of essential oil from Pogostemon cablin (Blanco) Benth and the stability of antimicrobial compositions. China Brewing, 8: 87-90.

Luo, C.K., 2005. Research on antibacterial test of water extract from Pogostemon cablin (Blanco) Benth. Zhong Yao Cai, 28: 700-701.

Mimee, B., R. Pelletier and R.R. Belanger, 2009. In vitro antibacterial activity and antifungal mode of action of flocculosin, a membrane-active cellobiose lipid. J. Applied Microbiol., 107: 989-996.
Mo, X.L., Z. Yan, Y.S. Wang and X.G. Wang, 2004. Research on anti-fungi activity of the essential of oil from Pogostemon cablin (Blanco) Benth against plant pathogenic fungi. Zhong Yao Cai, 27: 805-807.

Paranagama, P.A., K.H.T. Abeysekera, K. Abeywickrama and L. Nugaliyadde, 2003. Fungicidal and anti-aflatoxigenic effects of the essential oil of Cymbopogon itratus (DC.) Stapf. (lemongrass) against Aspergillus flavus Link isolated from stored rice. Lett. Applied Microbiol., 37: 86-90.

Pharmacopeia Commission of PRC, 2004. Pharmacopeia of the People's Republic of China, Part I. Chemical Industry Press, Beijing, China.

Smith-Palmer, A., J. Stewart and L. Fyfe, 1998. Antimicrobial properties of plant essential oils and essences against five important food-borne pathogens. Lett. Applied Microbiol., 26: 118-122.

Wei, A. and T. Shibamoto, 2007. Antioxidant activities and volatile constituents of various essential oils. J. Agric. Food Chem., 55: 1737-1742.

Yang, Y., K. Kinoshita, K. Koyama, K. Takahashi, T. Tai, Y. Nunoura and K. Watanabe, 1999. Anti-emetic principles of Pogostemon cablin (Blanco) Benth. Phytomedicine, 6: 89-93.

Yayli, N., A. Yasar, N. Y. Iskender, N. Yayli, T.B. Cansu, K. Coskuncelebi and S. Karaoglu, 2010. Chemical constituents and antimicrobial activities of the essential oils from Sedum pallidum var. bithynicum and $S$. spurium grown in Turkey. Pharm. Biol., 48: 191-194.

Zhao, Z., J. Lu, K. Leung, C.L. Chan and Z.H. Jiang, 2005. Determination of patchoulic alcohol in herba Pogostemonis by GC-MS-MS. Chem. Pharm. Bull., 53: $856-860$. 